\title{
Brief Report: L2 Vocabulary Acquisition by Reading, Listening, and Word- focused Activities
}

\author{
Kong Xianglong \\ Shanghai University of Medicine \& Health Sciences, Shanghai, China \\ kxl302213@163.com
}

Keywords: vocabulary acquisition, reading, listening, word-focused activities

\begin{abstract}
In this paper, the author surveys some experiments and studies in acquiring L2 vocabulary from reading, listening, and word-focused activities. By comparison, it is found that the vocabulary gains from reading are much larger than that from listening. Similarly, when reading is compared with a word-focused activity alone, it is the latter that is more effective for L2 vocabulary acquisition.
\end{abstract}

\section{Introduction}

Almost all second language learners have realized that learning a second language (L2) involves the learning of great number of words. Many learners are somewhat worried when they are faced with such a difficult task and teachers as well as learners are committed to finding out what the best way to learn words is. One of the fundamental questions in vocabulary acquisition is: "What is the main source of L2 vocabulary knowledge?” For decades, instructional practice has been based on the view that elaboration on features of new words promotes their retention (Anderson 1995). This proposition is based on William James' theory (1890) that "all improvement of memory lies in the line of elaborating the associates”. This means that the more attention that is paid to the form and semantic meaning the words and the richer the associations that are made with previously known knowledge, the higher are the chances that the new information will be retained.

On the other hand, all learners and teachers notice that motivation promotes performance in L2 learning and that students, who experience high amounts of an external driving force to learn, will achieve higher levels of performance than students with low levels of driving force. This means that teachers may attempt to increase students' motivation by providing intriguing tasks and materials to them. So elaboration and motivation are key factors in promoting vocabulary learning, and when we carry out researches of vocabulary acquisition, we should bear the two factors in mind. The followings surveys include vocabulary acquisition from reading, listening and word-focused activities, and all of these experiments and studies are all conducted on this basis.

\section{Incidental vocabulary acquisition from reading}

Studies on second language acquisition support the conclusion that most vocabulary learning occurs naturally when learners attempt to understand new words that they read or hear in context. Such learning is called "incidental” because it occurs as learners are focused on something instead of the meaning of words themselves. A very prominent view of vocabulary acquisition claims that we acquire most words through exposure to a large amount of language input, particularly reading input, rather than by deliberately memorize new words alone. This position is usually referred to as the default hypothesis since it is justified in negative terms: the number of words that are learnt is too vast to be accounted for by instruction (Nagy et al 1985). However, vast majority of such research has been implemented in the area of reading. Although results vary, the learning gains found are generally small.

More reasonable estimates of vocabulary acquisition from reading can be obtained by the studies that used long texts (Mason and Krashen, 1997). The studies compare the extensive reading method 
with more traditional teaching ways, though it is not so clear what is meant by these traditional ways of teaching. When they examine the progress in vocabulary, they do not test the knowledge of particular words but measure vocabulary progress in general. What's more, it is not always clear how the learners handle unknown words during the reading process. If the words are underlined, put down or looked up for meaning, then we cannot ascribe the reported learning to reading only.

Similarly, studies focusing specifically on the acquisition of words encountered in book reading also show very small gains. Horst, Cobb and Meara (1998) specifically looked at the number of words acquired from a simplified version of a novel, The Mayor of Casterbridge, which had 21000 running words. The novel was read in class during six class periods. It was found that the average vocabulary pick-up was five words. Lahav (1996) carried out a study of vocabulary learning from simplified readers. She tested students who read 4 readers, each one of about 20000 words, and found an average learning rate of 3-4 words per book.

The above survey indicates that reading is not likely to be the main source of L2 learners' vocabulary acquisition. If most words were acquired from reading, learners would have to read about as much as native children do - that is, a million words of text a year. This would require reading one or two books per week. If, however, teachers can expect only small quantities of reading, then word-focused activities should be regarded as a way of vocabulary learning.

\section{Incidental vocabulary acquisition from listening}

L2 listening has received relatively little research attention, and this is also true of the area of incidental vocabulary acquisition from listening. However, more recently, a few vocabulary studies have measured learning from listening directly. Their findings suggest that listening leads to even smaller gains than reading does (Brown, 2008; Vidal, 2011). Yet, similar to traditional reading research, these studies have used meaning-based tests only. This means that more learning may have occurred than has been discovered. The recent study uses more sensitive vocabulary tests in order to find how much learning really happens through listening, and how this compares to reading.

Vidal explored incidental vocabulary acquisition from L2 listening (2003), and compared gains from listening with reading (2011). These studies analyzed the effect of a large number of variables (e.g. frequency of occurrence, predictability from word form and parts) on learning. Knowledge gains of 36 target words were measured with a modified version of the Vocabulary Knowledge Scale, on which learners could effectively score 0 to 5 . Out of the maximum score of 180 , readers scored 40.85 (22.7\%) on the immediate post-test and $19.14(10.6 \%)$ on the one-month delayed test. Listeners scored 27.86 (15.5\%) immediately after listening and 14.05 (7.8\%) one month later. The main finding is that both reading and listening lead to vocabulary knowledge gains, with gains from reading being much larger than from listening. An effect of frequency occurrence $(1,2,3,4,5$, or 6 occurrences) was found in both modes but this was considerably stronger in reading. More repetitions were needed in listening ( 5 to 6 ) than in reading ( 2 to 3 ) for it to have a positive effect on learning.

Brown (2008) also compared vocabulary learning from reading and listening, finding that the former lead to significantly more vocabulary learning. Another difference is related to the frequency effect: this was found to exist in both input modes, but was smaller in the listening mode.

These studies indicate smaller learning gains from listening than from reading. Why could this be the case? Possible reasons are concerned with the nature of spoken language versus written one: spoken language requires fast processing, meaning that listeners simply have less time than readers to focus on linguistic information. It is also continuous (i.e. no obvious boundaries between words), likely making it more difficult to beware new words in the input. In addition, many L2 listeners are encountered with problems with speech segmentation, which often leads them to miss subsequent or forget previous parts of the input (Goh, 2000). Such problems can negatively affect comprehension and impede vocabulary acquisition. 


\section{Vocabulary acquisition from word-focused activities}

Incidental vocabulary acquisition is the acquisition of vocabulary as a by-product of another activity while intentional vocabulary acquisition refers to an activity aimed at committing lexical information to memory (Laufer and Hulstijn 2001). Therefore, it is clear that learning by wordfocused activities is by all means an intentional vocabulary acquisition. Whatever the significance of reading as an educational activity and as a means of vocabulary acquisition, as far as incidental vocabulary acquisition is concerned, there is sufficient evidence for the superiority of word-focused tasks over reading and listening.

Many studies surveyed demonstrated the superiority of word-focused activities over reading a text with new words, regardless of whether these words were glossed or had to be guessed. The more effective tasks involved looking up the words in a dictionary, filling the target words in the blanks of given sentences, using them in original output in the form of isolated sentences, or a composition that incorporated all the target words of the study. Researches that investigated vocabulary acquisition during oral tasks reached a similar conclusion - that is, doing something with the new words is more effective for learning than incidentally meet them in the input. According to Newton (1995), when the meaning of new words was negotiated during an oral activity, the words were remembered better than those whose meaning was not discussed and possibly left to guesswork. A task requiring an output in which the new word is used yielded higher word retention scores than a task which did not require language production, even though the new words occurred and had to be understood in the oral input (Ellis and He 1999).

It is striking to note that comparable results, which point to the superiority of word-focused activities over reading and listening, were gained in studies carried out in different sociolinguistic contexts. The subjects of some of the studies here were learners who learned English as a Foreign Language in the classroom context. Subjects of other studies learned English in an English-speaking environment.

Brown (2008) said he was unaware of any empirical studies which show that a particular number of exposures to a word in communication are more effective than a word-focused activity. Until such studies appear, we cannot give up the belief that doing something with a word is more effective than simply coming across it.

\section{Conclusion}

By reviewing the above experiments and studies, we can reach a conclusion that reading is not necessarily the main, nor the best, source of vocabulary learning in a second or foreign language. Research shows that word gains from reading activities alone are very small, regardless of whether learners read short or long texts. In order to acquire a word without attempting to commit it to memory, word-focused activities are recommended.

Experiments were presented that compared word gains from reading tasks with word gains from various word-focused tasks. Some of these types of tasks are: searching for the meaning or form of the target words in a dictionary; incorporating words in teacher-made sentences, or in original sentences, or in a composition. How do teachers know in advance which tasks will be effective for vocabulary learning? One proposal to explain and predict task effectiveness is the hypothesis of 'involvement'. The hypothesis claims that the presence of need, search and evaluation, together with their degree of prominence, constitute task-induced involvement load, which is the determining factor in vocabulary retention. Further research will confirm or refute the basic assumptions of the involvement hypothesis. There is, however, ample evidence to suggest that, whatever the explanation, word-focused activities may be a very good source of L2 vocabulary learning.

\section{References}

[1] Anderson, R C, P Wilson and L Fielding. 1988. 'Growth in reading and how hildren spend their 
time outside of school’. Reading Research Quarterly, 23:285-303.

[2] Brown, R., Waring, R., Donkaewbua, S. 2008. Incidental vocabulary acquisition from reading, reading-while-listening, and listening to stories. Reading a Foreign Language. 20:136-163.

[3] Ellis, R and X He. 1999. 'The roles of modified input and output in the incidental acquisition of word meanings'. Studies in Second Language Acquisition, 21:2: 285-301.

[4] Goh, C.C.M. 2000. 'A cognitive perspective on language learners' listening comprehension problems’. System, 28:55-75.

[5] Horst, M, T Cobb and P Meara. 1998. 'Beyond a clockwork orange: acquiring second language vocabulary through reading’. Reading in a Foreign Language, 11: 207-23.

[6] Hulstijn, J H and B Laufer.2001. 'Some empirical evidence for the Involvement Load Hypothesis in vocabulary acquisition’. Language Learning, 51:3: 539-58.

[7] James, W. 1890. Principles of Psychology. Vol. 1. New York: Holt.

[8] Lahav, J. 1996. 'Vocabulary acquisition through extensive reading: Incidental and controlled acquisition compared'. Unpublished MA thesis. University of Haifa.

[9] Mason, B., \& Krashen, S. 1997. 'Extensive reading in English as a foreign language'. System, 25:91-102.

[10] Nagy, W E, P A Herman and P C Anderson. 1985. 'Learning words from context'. Reading Research Quarterly, 20: 233-53.

[11] Newton, J. 1995. 'Task-based interaction and incidental vocabulary learning: A case study'. Second Language Research, 11: 159-77.

[12] Vidal, K. 2011. 'A comparison of the effects of reading and listening on incidental vocabulary acquisition’. Language Learning. 61: 219-258. 